\title{
BRCA2 Biallelic Inactivation
}

National Cancer Institute

\section{Source}

National Cancer Institute. BRCA2 Biallelic Inactivation. NCI Thesaurus. Code C142122.

The presence of mutations in both alleles of the BRCA2 gene that either lead to loss of expression of the BRCA2 protein or result in the translation of an inactive BRCA2 protein. 